удк 330.35

М. Г. ЖКигас

Байкальский государственный университет, г. Иркутск, Российская Федераиия

и. С. Самылкин

Байкальский государственный университет, 2. Иркутск, Российская Федерация

\title{
УПРАВЛЕНИЕ КЛИЕНТСКОЙ БАЗОЙ КРЕДИТНОЙ ОРГАНИЗАЦИИ
}

\begin{abstract}
АНнотАЦИЯ. Доверие к банку основывается на открытости, банк должен постоянно поддерживать тесный контакт с клиентами, что является для него вневременной ценностью, которая помогает в период спада экономического развития. В условиях кризиса присутствует тенденция к оттоку клиентов, что, безусловно, сокращает возможности банков. Именно в такой период им целесообразней реализовывать политику, которая направленна на удержание уже имеющихся клиентов, ведь известно, что привлечение новых клиентов обойдется намного дороже. Практика такова, что банки реагируют на жалобы клиентов, проявляя свою инициативность и заинтересованность в разрешении возникающих трудностей. Для обеспечения высококачественного обслуживания необходимо уделять особое, индивидуальное внимание клиенту. Демонстрация того, как клиент важен банку, для последнего является залогом успеха в формировании клиентской базы. Поэтому развитие качественного обслуживания, является важным, необходимым и достаточным условием для успешной работы коммерческого банка на всех стадиях развития отношений со своими клиентами, что и обуславливает актуальность темы исследования.
\end{abstract}

кЛючЕВЫЕ слОВА. Банковская система; коммерческие банки; управление; клиентская база.

ИНФОРМАЦИЯ О СТАТЬЕ. Дата поступления 31 июля 2017 г.; дата принятия к печати 11 октября 2017 г.; дата онлайн-размещения 25 октября 2017 г.

M. G. Zhigas

Baikal State University, Irkutsk, Russian Federation

S. I. Samylkin Baikal State University, Irkutsk, Russian Federation

\section{CLIENT BASE MANAGEMENT IN A CREDIT ORGANIZATION}

ABSTRACT. Trust in the bank is based on openness, the bank must constantly maintain close contacts with customers, which is its non-temporal value that helps during the period of economic downturn. In terms of the crisis, there is a tendency for customers' outflow, which, of course, reduces the capacity of banks. In this particular period it is more reasonable for them to actualize a policy aimed at retaining the existing customers, since it is known that attracting new customers would cost much more. The practice is that banks response to customers' complaints, thus showing their initiative and interest in resolving the evolving difficulties. To ensure high-quality service, it is necessary to pay a special, individual attention to the customer. Demonstration of how the customer is important for the bank is a success key in formation of the client base. Therefore, the development of quality service is an important, necessary and sufficient condition for successful operation of a commercial bank at all stages of developing relations with its customers, which determines the relevance of the research topic.

KEYWORDS. Banking system; commercial banks; management; client base.

ARTICLE INFO. Received July 31, 2017; accepted October 11, 2017; available online October 25, 2017.

(C) М. Г. Жигас, И. С. Самылкин, 2017

\section{Baikal Research Journal}


В общем смысле, клиентская база банка - это часть потенциальных потребителей рынков банковских услуг, которая находится в пределах возможных контактов с банком по территориальному признаку, и которую удовлетворяет набор предоставляемых банком услуг. Базу банка можно рассматривать с двух сторон. С одной стороны, это качественное состояние клиентов банка, как неслучайной совокупности потребителей используемых банковских услуг, а с другой, это работа банка с имеющимися клиентами [1].

Привлечение новых клиентов, как одно из условий построения клиентской базы банка, происходит различными способами. В качестве стимулирования могут выступать разного рода лотереи, подарки, особые скидки на продуктовую линейку банка. Для индивидуального побуждения персональных менеджеров к активности работы с наращиванием клиентской базы принадлежат конкурсы среди сотрудников подразделения, специальное премирование, а также моральное и материальное поощрение при перевыполнении плана продаж [2].

Для сохранения уже сформированной клиентской базы и привлечения новых клиентов, коммерческие банки ставят перед собой задачу как поиск возможных путей улучшения эффективности деятельности. Задача по определению эффективных направлений появляется перед банками из-за сильного конкурентного давления со стороны других банков [3].

Наиболее успешное продвижение банковской продукции на целевом рынке и его успех в борьбе за клиента будут определяться, в первую очередь, ценами на спрашиваемый продукт, прибыльностью банка, уровнем обслуживания, а также преимуществом в качестве предлагаемой услуги по сравнению с конкурентами. Помимо перечисленных условий, потенциальные клиенты обращают внимание на репутацию банка и его привлекательность (имидж), внешний вид и оформление его зданий, удобное расположение филиалов банка, пунктов обмена валюты и другие [4].

Для того чтобы верно и полно определить цель, мотивы поведения потенциального клиента нужно узнать ответы клиентов на вопросы:

1) Откуда клиент узнал об услугах банка?

2) С какой целью клиент обратился в банк?

3) О каких новых видах банковских услуг клиент хотел бы узнать?

4) каково будет отношение клиента к предлагаемым банком конкретным новым видам банковских услуг (согласие на рекламу);

5) удовлетворен ли клиент качеством обслуживания в банке и есть ли у него жалобы и или пожелания;

6) какое мнение у клиента о методике продвижения услуг на рынке, и его рекламы [5].

В процессе привлечения клиента проходит совместная работа отдела продаж и маркетинга. Сотрудники отдела продаж получают от службы маркетинга указание о перспективных клиентах и возможных объемах его привлечения, и стараются организовать работу с клиентом с помощью персональной продажи. Как правило, эти два вида отношений разрабатываются отдельно разными сотрудниками. Менеджеры, которые стараются привлечь клиента, и те, которые пытаются его удержать внутри банка [6].

Этапы формирования клиентской базы:

1) владельцы банка определяют миссию и цели деятельности, когда понятие клиентской базы еще не сформировано, а под ней понимается только часть потенциальных клиентов, на которую банк ориентируется;

2) анализом среды;

3) выбором стратегии;

\section{Baikal Research Journal}


4) реализация принятой стратегии. Клиентская база до сих пор сочетает в себе оба типа клиентов, но клиент постепенно приобретает статус реального;

5) клиентская база представляет собой организованную и упорядоченную совокупность реальных клиентов банка, исключая из списка потенциально-возможных групп [7].

Процесс формирования клиентской базы банка очень трудоемкий и предполагает постоянный контроль за ее состоянием, ведется тщательный мониторинг клиентуры [8].

Клиентская политика ПАО Банка «ФК Открытие» строится на следующих принципах:

1) развитие продуктовой линейки;

2) индивидуальный поход к клиентам;

3) построение системы перекрестных продаж;

4) создание экосистем вокруг потребностей клиентов;

5) мультиканальность;

6) лучший клиентский опыт.

ПАО Банком «ФК Открытие» постоянно совершенствует развитие своих продуктов, банк работает над расширением продуктового ряда и возможностью комбинирования продуктов друг с другом и настраивания их под нужды конкретных клиентов. ПАО Банком «ФК Открытие» развивает комиссионные и небанковские продукты. Все это позволяет ПАО Банку «ФК Открытие» предлагать клиентам пакеты услуг и продуктов, реализуя их любые потребности, связанные с финансами.

Благодаря эффективной системы перекрестных продаж, в основе которой лежит понимание потенциала каждого клиента банка и тех коммерческих активностей, которые важно исполнить для его реализации, а также благодаря умению анализировать поведение клиентов, ПАО Банк «ФК Открытие» способен создавать необходимые для клиентов новые продукты, услуги и пакеты услуг и своевременно их предлагать.

Сегментацию клиентской базы и ее анализ проведем в разрезе привлеченных и размещенных средств ПАО Банком «ФК Открытие».

Начнем анализ с рассмотрения размещенных средств ПАО Банком «ФК Открытие», поскольку они находятся в активах, и в первую очередь определим долю данного показателя в структуре активов банка.

Чистая ссудная задолженность за период с 2014 по 2016 г. увеличилась с 1843280 млн р. до 1867282 млн р., или на 1,3\%. При этом внутри периода темпы прироста существенно различались: с 2014 по 2015 г. произошел рост чистой ссудной задолженности на $26,3 \%$, в результате чего доля данного показателя выросла с 67,9 до 78,5 \%. Однако в 2016 г. произошло резкое снижение показателя до $69,7 \%$ в составе активов, что оказало прямое влияние на сокращение активов ПАО Банка «ФК Открытие», которые уменьшились с 2965870 млн р. в 2015 г. до 2677772 млн р. в 2016 г., или на $9 \%$. Сокращение чистой ссудной задолженности и как следствие активов, поскольку она занимает высокую долю в их составе, является негативной тенденцией, и важно изучить состав размещенных средств в разрезе клиентов и выявить за счет каких средств в основном произошло сокращение показателя, чтобы в дальнейшем скорректировать или внести изменения в управление клиентской базы для устранения негативных последствий ${ }^{1}$.

Структура чистой ссудной задолженности представлена в табл. 1.

${ }^{1}$ Годовая отчетность ПАО Банка «ФК Открытие» [Электронный ресурс] // Центральный банк Российской Федерации : офиц. сайт. URL: http://www.cbr.ru/credit/a2015.asp?regnum=2209.

\section{Baikal Research Journal}

электронный научный журнал Байкальского государственного университета 
Таблица 1

Структура чистой ссудной задолженности по видам клиентов

\begin{tabular}{|c|c|c|c|c|c|c|}
\hline \multirow[b]{2}{*}{ Виды клиентов } & \multicolumn{2}{|c|}{2014} & \multicolumn{2}{|c|}{2015} & \multicolumn{2}{|c|}{2016} \\
\hline & $\begin{array}{l}\text { Сумма, } \\
\text { млн р. }\end{array}$ & $\begin{array}{c}\text { Уд. вес., } \\
\%\end{array}$ & $\begin{array}{l}\text { Сумма, } \\
\text { млн р. }\end{array}$ & $\begin{array}{c}\text { Уд. вес., } \\
\%\end{array}$ & $\begin{array}{l}\text { Сумма, } \\
\text { млн р. }\end{array}$ & $\begin{array}{c}\text { Уд. } \\
\text { вес., \% }\end{array}$ \\
\hline $\begin{array}{l}\text { Средства, предоставленные } \\
\text { государственным органам и } \\
\text { организациям в государствен- } \\
\text { ной собственности }\end{array}$ & 11558 & 0,63 & 13681 & 0,59 & 26146 & 1,40 \\
\hline $\begin{array}{l}\text { Средства, предоставленные } \\
\text { корпоративным клиентам }\end{array}$ & 1696253 & 92,02 & 2171595 & 93,30 & 1717894 & 92,00 \\
\hline $\begin{array}{l}\text { Средства, предоставленные } \\
\text { розничным клиентам }\end{array}$ & 135470 & 7,35 & 142173 & 6,11 & 123242 & 6,60 \\
\hline Итого & 1843281 & 100 & 2327449 & 100 & 1867282 & 100 \\
\hline
\end{tabular}

Источник: Годовая отчетность ПАО Банка «ФК Открытие» [Электронный ресурс] // Центральный банк Российской Федерации : офиц. сайт. - Режим доступа: http://www.cbr.ru/credit/a2015. asp?regnum $=2209$.

Наибольший удельный вес в структуре чистой ссудной задолженности занимают средства, предоставленные корпоративным клиентам. Доля данного показателя несущественно изменялась внутри периода: с 2014 по 2015 г. средства, предоставленные корпоративным клиентам, возросли с 1696253 млн р. до 2171595 млн р. или на $28 \%$ (рис. 1), и как следствие, их доля возросла с $92,02 \%$ в 2014 г. до $93,3 \%$ в 2015 г.

Однако с 2015 по 2016 г. наблюдалось снижение средств, предоставленных корпоративным клиентам, на 20,1 \% (рис. 1 ), что в свою очередь вызвало снижение их доли до $92 \%$.

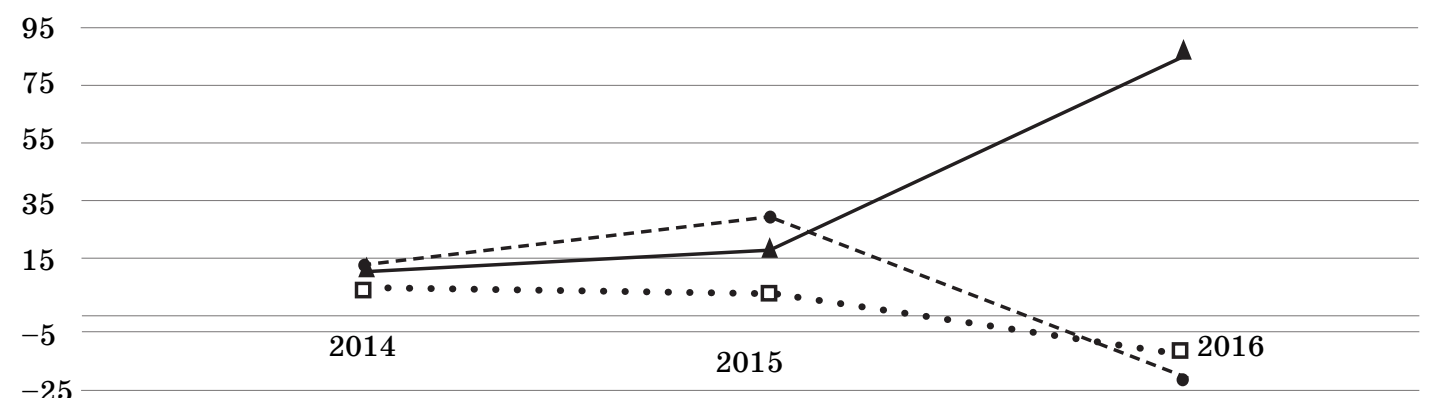

- - Предоставленных государственным органам и организациям в государственной собственности

- • - Предоставленных корпоративными клиентами

• ฉ. Предоставленных розничным клиентам

Рис. 1. Телпы прироста чистой ссудной задолженности по видал клиентов, \%

Источник: Годовая отчетность ПАО Банка «ФК Открытие»

[Электронный ресурс] // Центральный банк Российской Федерации : офии. сайт.

URL: http://www.cbr.ru/credit/a2015.asp? regnum=2209

Следующими по значимости в структуре размещенных средств идут средства, предоставленные розничным клиентам. Данный показатель с 2014 по 2016 г. снизился с 135470 млн р. до 123242 млн р., или на $9 \%$. Доля средств, предостав-

\section{Baikal Research Journal}


ленных физическим лицам, в 2014 г. составляла 7,35 \%, однако к 2016 г. доля снизилась до 6,6 \%. Такая ситуация сложилась вследствие превышения темпов прироста активов над темпами прироста средств, предоставленных физическим лицам. Средства, предоставленные государственным органам и организациям в государственной собственности, занимают небольшой удельный вес в составе чистой ссудной задолженности $(1,4 \%$ в 2016 г.), однако обладают самыми высокими темпами прироста $(91,1 \%$ в 2016 г.)

Остановимся подробнее на каждом из представленных показателей. Структура средств, предоставленных корпоративным клиентам, по видам организаций представлена в табл. 2.

Таблица 2

Структура средств, предоставленных корпоративным клиентам, по видам организаций

\begin{tabular}{|c|c|c|c|c|c|c|}
\hline \multirow[b]{2}{*}{ Виды организаций } & \multicolumn{2}{|c|}{2014} & \multicolumn{2}{|c|}{2015} & \multicolumn{2}{|c|}{2016} \\
\hline & $\begin{array}{l}\text { Сумма, } \\
\text { млн р. }\end{array}$ & $\begin{array}{c}\text { Уд. вес., } \\
\%\end{array}$ & $\begin{array}{l}\text { Сумма, } \\
\text { млн р. }\end{array}$ & $\begin{array}{c}\text { Уд. вес., } \\
\%\end{array}$ & $\begin{array}{l}\text { Сумма, } \\
\text { млн р. }\end{array}$ & $\begin{array}{c}\text { Уд. } \\
\text { вес., \% }\end{array}$ \\
\hline $\begin{array}{l}\text { Кредиты, предоставленные } \\
\text { негосударственным финансо- } \\
\text { вым организациям }\end{array}$ & 435593 & 25,68 & 743307 & 34,23 & 547889 & 31,89 \\
\hline $\begin{array}{l}\text { Кредиты, предоставленные } \\
\text { негосударственным коммер- } \\
\text { ческим организациям }\end{array}$ & 1011954 & 59,66 & 1135344 & 52,28 & 877848 & 51,10 \\
\hline $\begin{array}{l}\text { Кредиты, предоставленные } \\
\text { негосударственным неком- } \\
\text { мерческим организациям }\end{array}$ & 1230 & 0,07 & 3061 & 0,14 & 2829 & 0,16 \\
\hline $\begin{array}{l}\text { Кредиты и прочие средства, } \\
\text { предоставленные физиче- } \\
\text { ским лицам - индивидуаль- } \\
\text { ным предпринимателям }\end{array}$ & 4602 & 0,27 & 5902 & 0,27 & 5522 & 0,32 \\
\hline $\begin{array}{l}\text { Кредиты, предоставленные } \\
\text { юридическим лицам - нере- } \\
\text { зидентам }\end{array}$ & 242874 & 14,32 & 283981 & 13,08 & 283806 & 16,52 \\
\hline Итого & 1696253 & 100 & 2171595 & 100 & 1717894 & 100 \\
\hline
\end{tabular}

Источник: Годовая отчетность ПАО Банка «ФК Открытие» [Электронный ресурс] // Центральный банк Российской Федерации : офиц. сайт. URL: http://www.cbr.ru/credit/a2015.asp?regnum=2209.

Кредиты, предоставленные негосударственным финансовым организациям, также занимают большой удельный вес в структуре чистой ссудной задолженности корпоративных клиентов, при этом их доля выросла с 25,68 \% в 2014 г. до $31,89 \%$ в 2016 г. Наибольший темп прироста наблюдался в 2015 г.

Структура разработки предложений по совершенствованию формирования клиентской базы ПАО Банка «ФК Открытие» представлена на рис. 2.

Развитие кредитных операций, разрешение стратегических вопросов по формированию высокодоходного и качественного кредитного портфеля выполняется банком в условиях воздействия различных условий, которые формируются в обществе настоящих экономических предпосылок, степени конкурентной борьбы в банковской сфере, социального климата, необходимости поддержания на должном уровне ликвидности банка, имеется ввиду соотношения структуры активов со структурой источников средств.

\section{Baikal Research Journal}

электронный научный журнал Байкальского государственного университета 


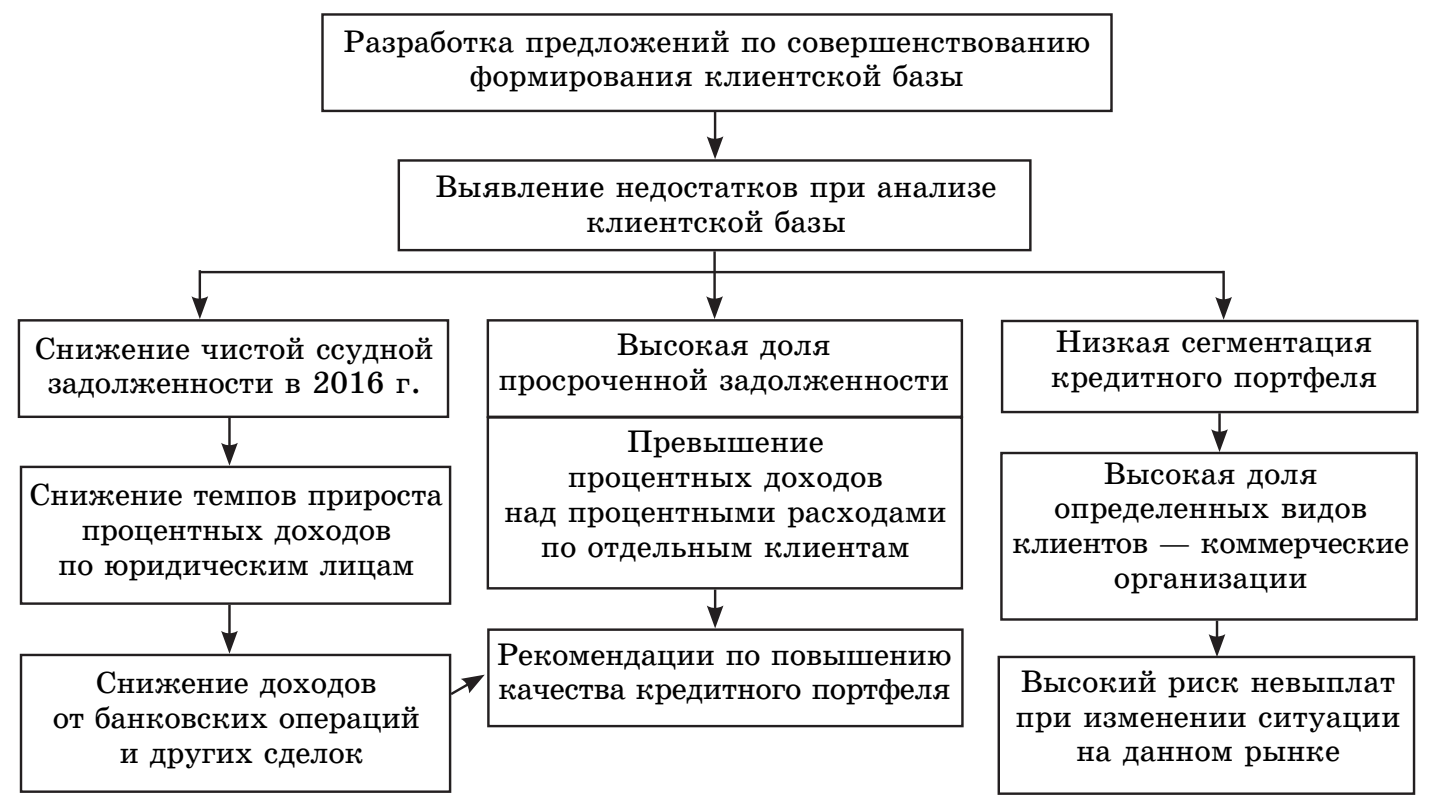

Рис. 2. Разработка предложений по совершенствованию формирования клиентской базы ПАО Банка «ФК Открытие»

Разглядывая задачу усовершенствования качества управления кредитным портфелем, немало важно осознавать, что качество кредитной деятельности зависит от качества управления кредитными рисками.

Главной задачей управления кредитными рисками в нынешних обстоятельствах считаются отсутствие системы всестороннего и полного рассмотрения кредитного процесса, солидной методологической базы и принятие ошибок в условиях неполной информации.

Из-за вероятно небезопасных для кредитной организации последствий кредитного риска в немаловажно постоянно выполнять всесторонний анализ процессов оценки, наблюдения, контроля, администрирования возврата кредитов, гарантий, авансов и прочих инструментов [9].

Конкурентная стратегия банка в розничном бизнесе будет основываться на формировании долгосрочных отношений с клиентами, кастомизации продуктового предложения, технологичности, качестве обслуживания [10].

\section{Список использованной литературы}

1. Чижов Н. А. Управление клиентской базов банка : практ. пособие / Н. А. Чижов. М. : Альфа-Пресс, 2007. - 284 с.

2. Имамбаева Р. Г. Пути развития клиентской базы банка в современных условиях глобальной финансовой интеграции / Р. Г. Имамбаева // Глобальные рынки и финансовый инжиниринг. - 2014. - № 1. - С. 63-72.

3. Орбинский С. С. Модель Кано: банковские продукты и потребности клиентов / С. С. Орбинский // Банковское дело. - 2011. - № 6. - С. 71-72.

4. Бедрикова Н. А. Установление взаимоотношений банка с клиентами / Н. А. Бедрикова, Ю. В. Корокошко // Системное управление. - 2011. - № 4. - С. 1-11.

5. Моисеенко Т. А. Проблемы расширения клиентской базы в банков-ском секторе / Т. А. Моисеенко // Символ науки. - 2016. - № 2-2. - С. 193-196.

\section{Baikal Research Journal}


6. Бондаренко Т. Н. Роль маркетинговых стратегий в организации работы коммерческого банка с клиентами / Т. Н. Бондаренко, А. А. Скоробогатова // Международный журнал прикладных и фундаментальных исследований. - 2015. - № 3-3. - С. 419-423.

7. Кривошапова С. В. Методы и подходы к формированию клиентской политики коммерческого банка (на примере ВТБ (ПАО) / С. В. Кривошапова, Е. Ю. Головко, Е. О. Казачинина // Фундаментальные исследования. - 2016. - № 6, ч. 2. - С. 391-396.

8. Трошин Д. С. Формализация процесса формирования эффективной базы коммерческого банка / Д. С. Трошин // Известия Тульского гос. ун-та. Серия «Экономические и юридические науки». - 2010. - № 2-2. - С. 297-303.

9. Федорова П. А. Риски и проблемы банковской системы в 2015 г. / П. А. Федорова, О. Г. Солнцева // Вестник университета. — 2016. — № 6. — С. 157-161.

10. Шорохова А. А. Влияние состава клиентской базы на формирова-ние услуг коммерческого банка / А. А. Шорохова // Банковская система России и современные особенности ее функционирования. - 2016. - № 1. - С. 131-135.

\section{References}

1. Chizhov N. A. Upravlenie klientskoi bazov banka [Management of bank client base: a practical guide]. Moscow, Alfa-Press Publ., 2007. 284 p.

2. Imambaeva R. G. Ways of development of bank client base in the context of global financial integration. Global'nye rynki $i$ finansovyi inzhiniring = Global Markets and Financial Engineering, 2014, no. 1, pp. 63-72. (In Russian).

3. Orbinskii S. S. The Kano model: banking products and customers' needs. Bankovskoe delo = Banking, 2011, no. 6, pp. 71-72. (In Russian).

4. Bedrikova N. A., Korokoshko Yu. V. Establishment of relationship between bank and clients. Sistemnoe upravlenie = System Management, 2011, no. 4, pp. 1-11. (In Russian).

5. Moiseenko T. A. Problems of client base expansion in banking sector. Simvol nauki= Symbol of Science, 2016, no. 2-2, pp. 193-196. (In Russian).

6. Bondarenko T. N., Skorobogatova A. A. Role of marketing strategies in work organization of the commercial bank with clients. Mezhdunarodnyi zhurnal prikladnykh $i$ fundamental'nykh issledovanii = International Journal of Applied and Fundamental Research, 2015, no. 3-3, pp. 419-423. (In Russian).

7. Krivoshapova S. V., Golovko E. Yu., Kazachinina E. O. Methods and approaches to client policy formation by the commercial bank (based on the example of VTB (PAO)). Fundamental'nye issledovaniya $=$ Fundamental Research, 2016, no. 6, part 2, pp. 391-396. (In Russian).

8. Troshin D. S. Formalization of the formation process for an effective commercial bank base. Izvestiya Tul'skogo gosudarstvennogo universiteta. Seriya «Ekonomicheskie i yuridicheskie nauki» = Bulletin of Tula State University. Series "Economic and Legal Sciences», 2010, no, 2-2, pp. 297-303. (In Russian).

9. Fedorova P. A., Solntseva O. G. Risks and problems of banking system in 2015. Vestnik universiteta $=$ Bulletin of the University, 2016, no. 6, pp. 157-161. (In Russian).

10. Shorokhova A. A. Influence of the client base composition on developing the commercial bank's services. Bankovskaya sistema Rossii $i$ sovremennye osobennosti ee funktsionirovaniya $=$ Russia's Banking System and Modern Features of its Functioning, 2016, no. 1, pp. 131-135. (In Russian).

\section{Информация об авторе}

Жигас Маргарита Герутисовна - доктор экономических наук, профессор, заведующий кафедрой банковского дела и ценных бумаг, Байкальский государственный университет, 664003, г. Иркутск, ул. Ленина, 11, e-mail: GigasMG@bgu.ru.

Сальлкин Игорь Сергеевич - студент, кафедра банковского дела и ценных бумаг, Байкальский государственный университет, 664003, г. Иркутск, ул. Ленина, 11, e-mail: igor. sergeeich.irk@mail.ru.

\section{Baikal Research Journal}




\section{Authors}

Margarita G. Zhigas - Doctor habil. in Economics, Professor, Head Chair of Banking and Securities, Baikal State University, 11 Lenin St., 664003, Irkutsk; e-mail: GigasMG@bgu.ru.

Igor Sergeyevich Samylkin - Student, Chair of Banking and Securities, Baikal State University, 11 Lenin St., 664003, Irkutsk; e-mail: igor.sergeeich.irk@mail.ru.

\section{Для цитирования}

Жигас М. Г. Управление клиентской базой кредитной организации / М. Г. Жиигас, И. С. Самылкин // Baikal Research Journal. - 2017. - T. 8, № 3. - DOI : 10.17150/2411$\underline{6262.2017 .8(3) .1 .}$

\section{For citation}

Zhigas M. G., Samylkin I. S. Client base management in credit organization / M. S. Zhigas, I. S. Samylkin. Baikal Research Journal. 2017, vol. 8, no. 3. DOI : 10.17150/24116262.2017.8(3).1. (In Russian).

\section{Baikal Research Journal}

